\title{
Prevalence and risk factors for Staphylococcus aureus nasopharyngeal carriage during a PCV trial
}

\author{
Abdoulie Bojang1', Lindsay Kendall', Effua Usuf ${ }^{1,2}$, Uzochukwu Egere1', Sarah Mulwa', Martin Antonio', \\ Brian Greenwood ${ }^{2}$, Philip C. Hill ${ }^{1,3}$ and Anna Roca ${ }^{1, *^{*}}$
}

\begin{abstract}
Background: We conducted an ancillary study among individuals who had participated in a cluster-randomized PCV-7 trial in rural Gambia (some clusters were wholly-vaccinated while in others only young children had been vaccinated), to determine the prevalence and risk factors for Staphylococcus aureus nasopharyngeal carriage.

Methods: Two hundred thirty-two children aged 5-10 years were recruited and followed from 4 to 20 months after vaccination started. We collected 1264 nasopharyngeal swabs (NPS). S. aureus was isolated following conventional microbiological methods. Risk factors for carriage were assessed by logistic regression.

Results: Prevalence of S. aureus carriage was $25.9 \%$. In the univariable analysis, prevalence of S. aureus carriage was higher among children living in villages wholly-vaccinated with PCV-7 [OR $=1.5795 \% \mathrm{Cl}(1.14$ to 2.15$)]$ and children with least 1 year of education $[\mathrm{OR}=1.4495 \% \mathrm{Cl}(1.07$ to 1.92)]. S. aureus carriage was also higher during the rainy season $[\mathrm{OR}=1.59 \mathrm{95 \%} \mathrm{Cl}(1.20$ to 2.11$)]$. Carriage of $\mathrm{S}$. pneumoniae did not have any effect on $\mathrm{S}$. aureus carriage for any pneumococcal, vaccine-type (VT) or non-vaccine-type (NVT) carriage. Multivariate analysis showed that the higher prevalence of $\mathrm{S}$. aureus observed among children living in villages wholly-vaccinated with PCV-7 occurred only during the rainy season OR $2.7295 \% \mathrm{Cl}(1.61-4.60)$ and not in the dry season OR $1.2895 \% \mathrm{Cl}(0.78-2.09)$.

Conclusions: Prevalence of nasopharyngeal carriage of $S$. aureus among Gambian children increased during the rainy season among those children living in PCV-7 wholly vaccinated communities. However, carriage of S. aureus is not associated with carriage of S. pneumoniae.
\end{abstract}

Trial registration: ISRCTN51695599. Registered August 04th 2006.

Keywords: S. aureus, PCV, Nasopharyngeal carriage, Seasonality, Risk factor, The Gambia

\section{Background}

Staphylococcus aureus is one of the most common bacteria associated with neonatal sepsis [1-3] and child pneumonia $[4,5]$ in sub-Saharan Africa. It is also a leading cause of community and hospital-based skin and soft tissue infections [6]. S. aureus is a common colonizer of the upper respiratory tract [7]. This asymptomatic colonization is a necessary step on the pathway to disease [8] with

\footnotetext{
* Correspondence: aroca@mrc.gm

${ }^{1}$ Medical Research Council Unit, P. O. Box 273, Fajara, The Gambia

${ }^{4}$ Faculty of Epidemiology and Population Health, London School of Hygiene and Tropical Medicine, London, UK

Full list of author information is available at the end of the article
}

nasopharyngeal carriage [9], nasal and rectal carriage [10] being linked to subsequent $S$. aureus disease.

Asymptomatic carriage of $S$. aureus varies extensively between populations, age groups, gender, vaccination with pneumococcal vaccines, socioeconomic factors and may also show seasonal variation. In the USA, Taiwan, Mexico, and Gabon nasopharyngeal carriage rates in the general populations among participants age 1-90 years were reported to be $30.4 \%, 24.1 \%, 37.1 \%$ and $29.0 \%$ respectively [11-14]. In Cape Verde, prevalence of nasal carriage of $S$. aureus was reported to be higher among hospitalized individuals and health care workers than in the general population [15]. Nasopharyngeal carriage was also found to be elevated in an urban setting [16] and among HIV infected 
individuals [17]. In The Gambia, prevalence of $S$. aureus nasopharyngeal carriage was highest at birth and decreased during the first few weeks of life [18], although prevalence remains high during infancy [19].

The introduction of pneumococcal conjugate vaccines (PCVs) alters the microbial flora in the nasopharynx [20, 21] with a substantial decrease of pneumococcal serotypes included in the vaccine (vaccine types or VT) [22], and an increase in other pneumococcal serotypes (non-vaccine types or NVT) [23-25]. Among PCV naive population, several studies have shown that colonization with $S$. aureus is inversely associated with Streptococcus pneumoniae colonization [19, 26-30]. In addition, in one study, S. aureus carriage increased post pneumococcal vaccination with the highest differences between vaccinated and non-vaccinated children being found at the age of 12 months [31]. Although the inverse association between colonization with these two bacteria has been reported worldwide, the exact mechanism is yet to be understood. Some reports showed that production of hydrogen peroxide by the pneumococcus is directly bactericidal to $S$. aureus [32] and the presence of the pneumococcal pilus directly induce a host immune response that is deleterious to S. aureus colonization [33]. Lebon and colleagues [34] could not explain this inverse association between S. aureus and S. pneumoniae by measuring antipneumococcal antibodies with $S$. aureus colonizing and anti-staphylococcal antibodies with $S$. pneumoniae colonizing among healthy children.

Many of the studies showing the inverse association between these two bacteria are either small or the statistical analysis does not adjust for potential confounders. In a recent report from The Gambia, we showed that the inverse association found in the crude analysis was explained by the different carriage profile during the first year of life, with $S$. aureus decreasing in prevalence from birth and $S$. pneumoniae increasing, both reaching a plateau at around 20 weeks of age [35]. In this study, when age and other potential confounders were considered in the adjusted analysis, there was no association between the two bacteria with any of the S. pneumoniae endpoints analysed (overall carriage, VT carriage and NVT carriage). A number of other studies found no association between S. pneumoniae and S. aureus in either carriage [35, 36] or disease [37, 38].

The aim of the analysis presented here is to assess the prevalence and risk factors of nasopharyngeal carriage of $S$. aureus among children (5-10 years of age) living in rural Gambia who participated in a PCV-7cluster randomized trial.

\section{Methods}

\section{Trial design}

The analysis presented here is ancillary to a large, singleblinded, cluster-randomized (by village), placebo-controlled trial of PCV-7 conducted to assess the impact of vaccination on pneumococcal nasopharyngeal carriage. Details of the study design, and the overall impact of vaccination have been described previously [20, 39]. In brief, 21 villages in rural Gambia were randomized to two arms. Three doses of PCV-7 were given to all children below 30 months of age at the start of vaccination (July 2006) and to all those born in the study villages during the follow-up period (until July 2008) irrespective of the trial arm because PCV had been shown to be effective in this age group in a previous trial conducted in the country [40]. Vaccination in older children and adults depended on trial arm. In wholly vaccinated communities, all inhabitants received PCV-7. In partly vaccinated villages, the older age groups received one dose of serogroup C Meningococcal Conjugate Vaccine. PCV-7 vaccine was introduced in The Gambia as part of the Expanded Programme of Immunization across the whole country in August 2009 and replaced by PCV-13 in June 2011 [18].

\section{Longitudinal study}

Approximately, 5441 inhabitants lived in the study villages. Six hundred and thirty-six subjects above the age of 30 months at the start of the trial were randomly selected from the 21 study villages for participation in the longitudinal study. Selection of participants was proportional to the number of subjects in each village for the different age groups ( 2.5 years to less than 5 years, 5 to less than 15 years and 15 years and above [41]). All subjects aged 5-10 years who had at least one NPS collected were included in the ancillary study presented here (232 subjects). We selected this age group for two main reasons: (i) both prevalence of $S$. pneumoniae and S. aureus nasopharyngeal carriage are high and (ii) it discriminates children vaccinated with PCV-7 (wholly vaccinated villages) versus children not vaccinated with PCV-7 (partly vaccinated villages).

\section{Ethical approval}

Parental consent was obtained for children who participated in the original study which was approved by the joint MRC/Gambia Government Ethics Committee and by the ethics committee of the London School of Hygiene \& Tropical Medicine.

\section{Sample handling}

NPS were collected monthly during the first 3-4 months of follow-up (starting in November 2006) and then every 3 months until June 2008 [41]. Samples collection was done as described previously [20] in accordance with a WHO protocol [42]. The posterior wall of the nasopharynx was swabbed using a sterile calcium alginate swab and immediately inoculated into vials containing $1 \mathrm{ml}$ of skim milktryptone-glucose-glycerol (STGG) transport medium. These vials were then placed in a cold box before being transferred 
to the Medical Research Council Laboratories in Fajara (a distance of $90 \mathrm{~km}$ ) within $8 \mathrm{~h}$ of collection. The vials were then vortexed for a minimum of $20 \mathrm{~s}$ before being stored at $-70{ }^{\circ} \mathrm{C}$ until tested in batches.

\section{Laboratory methods}

Frozen STGG containing NPS were initially thawed on ice and then vortexed briefly for a minimum of $20 \mathrm{~s}$. $50 \mu \mathrm{l}$ of thawed medium was then plated on Mannitol Salt Agar (MSA) [CM0085, Oxoid UK] plates, the inoculum streaked into four quadrants in order to semi quantitatively determine the bacterial load before being incubated aerobically at $37{ }^{\circ} \mathrm{C}$ for $48 \mathrm{~h}$ [39]. The plates were later examined for pale to golden yellow doomed shaped colonies 1-2 mm in diameter. A catalase test was performed on all suspected colonies. Catalase positive colonies were tested further using the Staphaurex ${ }^{\bullet}$ plus kit [OXR30950201, Oxoid UK], a rapid latex agglutination test for the identification of $S$. aureus. Positive isolates were confirmed $S$. aureus.

\section{Data management and statistical analysis}

The primary aim of this analysis was to assess the prevalence of nasopharyngeal carriage of $S$. aureus and determine risk factors in the study population. The rainy season was defined as the period from June to October and the dry season from November to May.

Firstly, summary statistics [median and IQR for the quantitative variables and (n\%) for categorical variables] were estimated within each variable group. The distributions of these variables were compared between groups (S. aureus carriers versus non-carriers) using the Wilcoxon rank-sum test or Chi-square/Fisher's exact test.

Further, logistic regression analysis with subject as a random effect was applied to quantify the association of $S$. aureus carriage with all the co-variables, reporting odds ratios (OR) and their 95\% confidence intervals (95\%CI) while adjusting for potential confounders. Covariables that showed association with $S$. aureus carriage in the univariate analysis ( $p$-value $\leq 0.05$ were included in the multivariate analysis. Several plausible interaction terms were tested in the multivariable analysis using likelihood ratio tests at $\alpha=0.050$. The selection of interaction terms to be tested was exploratory.

A multilevel, random intercept, logistic regression modelling technique was applied to account for the correlations of samples collected from the same subject over time and the clustering of subjects within the same village. However, likelihood ratio tests (though conservative) showed little evidence $(P$-value $>0.1)$ of within village clustering of subjects. Hence the random intercept models were simplified by ignoring the within village clustering of subjects. There was little evidence of an autocorrelation structure and an equal (independent) correlation structure was assumed. Furthermore, robust variance estimator were tested, but gave very similar results to the model based standard errors.

All the analyses were conducted in Stata 12.1 (StataCorp. Texas, USA). Figures were done in $\mathrm{R}$ statistical programming software ( $\mathrm{R}$ Core Team 2014). Pvalues $<0.05$ have been taken to indicate statistical significance.

\section{Results}

A total of 232 children [median age 5.7 years (range 510)] took part in the study, with $131(56.5 \%)$ of the participants being residents in the PCV-7 wholly vaccinated

Table 1 Baseline characteristics of the study participants

\begin{tabular}{|c|c|c|}
\hline Variables & $\mathrm{N}$ & $\%$ \\
\hline $\mathrm{N}$ & 232 & - \\
\hline \multicolumn{3}{|l|}{ Sex } \\
\hline Male & 123 & 53.0 \\
\hline Female & 109 & 47.0 \\
\hline Median age (Range) & 5.7 (5-10 yrs) & - \\
\hline Samples collected per child Median (Range) & $6.0(1-10)$ & - \\
\hline Overall carriage & 232 & 25.9 \\
\hline Missing data & 11 & 0.01 \\
\hline \multicolumn{3}{|l|}{ Group } \\
\hline Wholly vaccinated & 131 & 56.5 \\
\hline Partially vaccinated & 101 & 43.5 \\
\hline \multicolumn{3}{|l|}{ Ethnicity } \\
\hline Jola & 165 & 71.1 \\
\hline Fula & 11 & 4.7 \\
\hline Mandinka & 46 & 19.8 \\
\hline Other & 10 & 4.3 \\
\hline \multicolumn{3}{|l|}{ Attended school } \\
\hline Yes & 141 & 60.8 \\
\hline No & 91 & 39.2 \\
\hline \multicolumn{3}{|l|}{ Smoker in house hold } \\
\hline Yes & 104 & 44.8 \\
\hline No & 128 & 55.2 \\
\hline \multicolumn{3}{|l|}{ Education } \\
\hline None & 86 & 37.1 \\
\hline$<1 \mathrm{yr}$ & 42 & 18.1 \\
\hline$>=1$ & 104 & 44.8 \\
\hline \multicolumn{3}{|l|}{ Ability to read } \\
\hline Yes & 74 & 31.9 \\
\hline No & 158 & 68.1 \\
\hline \multicolumn{3}{|l|}{ Ability to write } \\
\hline Yes & 61 & 26.3 \\
\hline No & 171 & 73.7 \\
\hline
\end{tabular}


villages. One hundred and twenty three participants (53.0\%) were male; Jolas were the most common ethnic group (71.1\%). Overall, we collected 1264 NPS [median $=6$ per participant; range 1-10]. Demographic and epidemiological characteristics of the study participants are shown in Table 1.

Table 2 Univariable analysis for association of S. aureus carriage with covariables

\begin{tabular}{|c|c|c|c|c|c|c|c|}
\hline \multirow[t]{2}{*}{ Variables } & S. aureus ${ }^{+}$ & $\%$ & S. aureus ${ }^{-}$ & $\%$ & Total & OR & $95 \% \mathrm{Cl}$ \\
\hline & \multicolumn{2}{|l|}{$\mathrm{n}$} & \multicolumn{5}{|l|}{$n$} \\
\hline $\mathrm{N}$ & 347 & 27.5 & 917 & 72.5 & 1264 & & \\
\hline Age (years) & & & & & & 1.05 & $0.96,1.15$ \\
\hline \multicolumn{8}{|l|}{ Sex } \\
\hline Male & 194 & 29.5 & 464 & 70.5 & 658 & & \\
\hline Female & 153 & 25.3 & 453 & 74.7 & 606 & 0.81 & $0.59,1.11$ \\
\hline \multicolumn{8}{|l|}{ Group } \\
\hline Partially vaccinated & 221 & 30.9 & 495 & 69.1 & 716 & & \\
\hline Wholly vaccinated & 126 & 23.0 & 422 & 77.0 & 548 & 1.57 & $1.14,2.15$ \\
\hline \multicolumn{8}{|l|}{ Ethnicity } \\
\hline Jola & 229 & 26.2 & 646 & 73.8 & 875 & & \\
\hline Fula & 17 & 33.3 & 34 & 66.7 & 51 & 1.42 & $0.67,3.02$ \\
\hline Mandinka & 81 & 29.2 & 196 & 70.8 & 277 & 1.15 & $0.78,1.69$ \\
\hline Other & 20 & 32.8 & 41 & 67.2 & 61 & 1.51 & $0.74,3.10$ \\
\hline \multicolumn{8}{|l|}{ Attended school } \\
\hline Student & 266 & 28.3 & 673 & 71.7 & 939 & & \\
\hline Non-student & 81 & 23.3 & 244 & 76.7 & 325 & 0.83 & $0.60,1.16$ \\
\hline \multicolumn{8}{|l|}{ Smoker in household } \\
\hline No & 189 & 28.0 & 487 & 72.0 & 676 & & \\
\hline Yes & 158 & 26.9 & 430 & 73.1 & 588 & 1.01 & $0.76,1.34$ \\
\hline \multicolumn{8}{|l|}{ Education } \\
\hline$<1 \mathrm{yr}$ & 120 & 23.8 & 384 & 76.2 & 504 & & \\
\hline$>=1 \mathrm{yr}$ & 227 & 29.9 & 533 & 70.1 & 760 & 1.42 & $1.06,1.91$ \\
\hline \multicolumn{8}{|l|}{ Ability to read } \\
\hline No & 160 & 24.7 & 488 & 75.3 & 648 & & \\
\hline Yes & 187 & 30.4 & 429 & 69.6 & 616 & 1.32 & $1.00,1.74$ \\
\hline \multicolumn{8}{|l|}{ Ability to write } \\
\hline No & 198 & 25.6 & 574 & 74.4 & 952 & & \\
\hline Yes & 149 & 30.3 & 343 & 69.7 & 492 & 1.25 & $0.93,1.68$ \\
\hline \multicolumn{8}{|l|}{ Season } \\
\hline Dry & 221 & 24.8 & 669 & 75.2 & 890 & & \\
\hline Rainy & 126 & 33.7 & 248 & 66.3 & 374 & 1.59 & $1.20,2.11$ \\
\hline \multicolumn{8}{|l|}{ Any pneumococci } \\
\hline No & 129 & 30.4 & 296 & 69.6 & 425 & & \\
\hline Yes & 218 & 26.0 & 621 & 74.0 & 839 & 0.81 & $0.61,1.07$ \\
\hline \multicolumn{8}{|l|}{ Vaccine type $(V T)$} \\
\hline No & 311 & 27.3 & 829 & 72.7 & 1140 & & \\
\hline Yes & 36 & 29.0 & 88 & 71.0 & 124 & 1.10 & $0.71,1.72$ \\
\hline \multicolumn{8}{|l|}{ Non-vaccine type (NVT) } \\
\hline No & 156 & 29.9 & 366 & 70.1 & 522 & & \\
\hline Yes & 191 & 25.7 & 551 & 74.3 & 742 & 0.81 & $0.62,1.07$ \\
\hline
\end{tabular}


Prevalence of $S$. aureus nasopharyngeal carriage was $25.9 \%$ in the study population. In the crude analysis, prevalence of $S$. aureus nasopharyngeal carriage was similar between genders and age groups (Table 2). Higher prevalence of $S$. aureus carriage was found among children from villages wholly vaccinated with PCV-7 [30.9\% vs. $23.0 \%$ OR $1.5795 \%$ CI (1.14 to 2.15 )] and children who had attended school for at least 1 year [ $29.9 \%$ vs. $23.8 \%$ OR 1.42 95\%CI (1.06 to 1.91)]. In addition, prevalence of $S$. aureus nasopharyngeal carriage was higher during the rainy season compared to the dry season [33.7\% vs. $24.8 \%$ OR 1.59 95\%CI (1.20 to 2.11)]. Prevalence of S. aureus carriage was similar between children who were carriers or non-carriers of S. pneumoniae (either for any pneumococcal carriage, VT carriage or NVT carriage) (Table 2).

The multivariate analysis (including the analysis for interactions) showed that the higher prevalence of $S$. aureus nasopharyngeal carriage among children from PCV-7 wholly vaccinated compared to $\mathrm{PCV}-7$ partially vaccinated communities only occurred during the rainy season [OR $2.7295 \% \mathrm{CI}(1.61$ to 4.60$)$ ] and not in the dry season [OR:1.19 (0.82, 1.71)] (Fig. 1) (Table 3).

\section{Discussion}

This paper reports the prevalence of $S$. aureus nasopharyngeal carriage within the context of a PCV-7 cluster-randomized-trial in sub-Saharan Africa. Rural communities in The Gambia were randomized to higher or lower PCV-7 pressure (wholly versus partially vaccinated communities). Our findings support those of previous studies conducted in the country which showed that $S$. aureus carriage among children is high and not associated with S. pneumoniae carriage [35]. Nonetheless, in this study prevalence of $S$. aureus carriage was higher among children from communities with the highest PCV-7 pressure (wholly vaccinated communities) during the rainy but not the dry season.

Our results show that $25.9 \%$ of the Gambian children included in the study were carriers of $S$. aureus at any time point during the follow up period. It is difficult to make any valid comparison between this and other studies in the country since they differ either in the laboratory methods used, age, setting or exposure to PCV. In a similar study in the same setting among infants not exposed to PCV, prevalence of carriage was 30.9\% [35]. In another study conducted in peri-urban Gambia among infants exposed to PCV-7, nasopharyngeal carriage of $S$. aureus was $33.6 \%$ whereas oropharyngeal carriage was $65.0 \%$ [43]. In Nigeria, S. aureus nasopharyngeal carriage among students aged 9-32 years attending various educational establishments was $56.4 \%$ [44].

Our study revealed that despite the introduction of PCV-7, no association between $S$. aureus and S. pneumoniae nasopharyngeal carriage was observed for any of the S. pneumoniae end points. These results are in line with previous data in the same villages before PCV introduction which showed no association between these two bacteria among infants [35]. Our trial had previously showed a strong herd effect of PCV-7 introduction in communities partly vaccinated with PCV-7 [20, 45] which turned into similar pneumococcal serotype distribution in the two trial arms. Therefore, the reasons for higher prevalence of S. aureus in PCV-7 wholly vaccinated communities during the rainy season are unclear. One possible explanation would be that risk factors of S. aureus carriage differ between study arms, and thus prevalence of carriage was already different between trial arms before PCV-7 introduction. However, this is unlikely due to the nature of the trial where clusters were

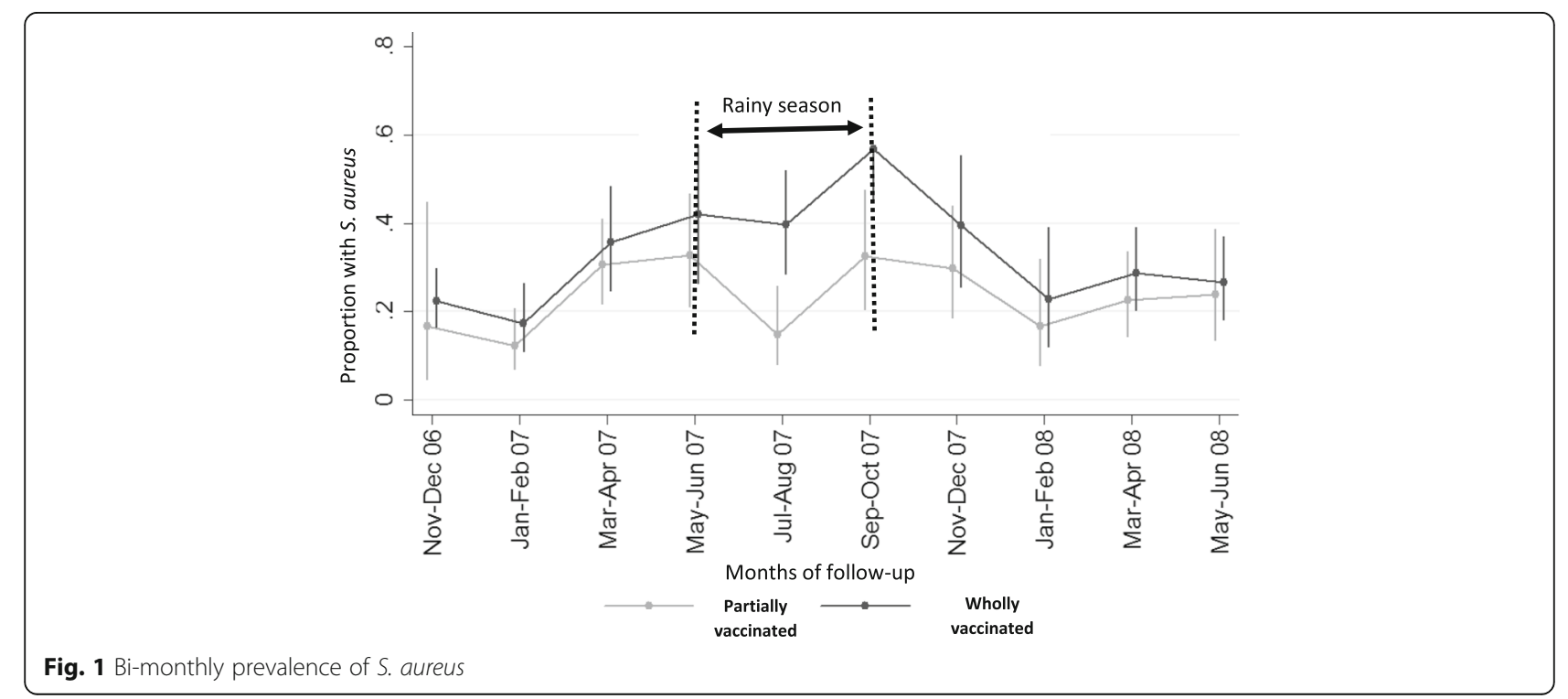


Table 3 Final multivariable analysis model showing factors associated with S. aureus carriage

\begin{tabular}{llllll}
\hline Variable & & & $\mathrm{n}$ & $\mathrm{OR}$ & $95 \% \mathrm{Cl}$ \\
\hline Season & Dry & Partially vaccinated & 399 & & \\
& & Wholly vaccinated & 491 & 1.19 & $0.82,1.71$ \\
& \multirow{2}{*}{ Wet } & Partially vaccinated & 149 & & \\
& & Wholly vaccinated & 225 & 2.72 & $1.61,4.60$ \\
\hline
\end{tabular}

randomly selected. It could also be a chance finding and we note that a number of variables were studied without a prior hypothesis. Further studies will be needed to explain these findings.

In our analysis, carriage of $S$. aureus follows a seasonal pattern which peaks during the rainy season unlike $S$. pneumoniae which peaks in the dry season [41]. In line with this seasonality of carriage, Chan and colleagues $[46,47]$ reported increased maternal S. aureus colonization $(\mathrm{RR}=1.96,95 \%$ CI 1.29 to 2.95$)$ during the rainy season in Bangladesh and a study in Australia also reported an increase of $S$. aureus infection during the rainy season [48]. In our setting, infections with respiratory viruses such as RSV, influenza A, influenza B or adenoviruses are higher during the rainy season when humidity increases [49]. Initial colonization with respiratory viruses or decreased immune competence due to poor diet during the rainy season may have resulted in the increased transmission of $S$. aureus [50, 51]. However, we did not assess either viral infection or diet in study participants.

Our study was limited by a number of factors related to the design. First, we limited this ancillary analysis to children 5-10 years of age for two main reasons. Bacterial transmission among children tends to be higher than in adults. Also, in this age group children had only received PCV-7 if they live in the fully vaccinated villages which is not the case among younger children. On the other hand, our results on seasonality are based in a short time period. A longer follow up would have been more robust in establishing a seasonal pattern. The study only collected NPS for the detection S. aureus. Although prevalence of carriage would have likely been higher if the samples collected were oropharyngeal swabs, we do not expect different associations in the risk factors analysis.

\section{Conclusion}

Our findings show that transmission of S. aureus in our setting is high which may explain the high burden of associated disease [49]. In addition, we did not find any association between $S$. aureus and $S$. pneumoniae nasopharyngeal carriage. The effect of PCV introduction on S. aureus transmission in rural Gambia will need to be further studied after the recent introduction of PCV-13 as part of the Expanded Programme of Immunization to determine if our findings are confirmed.

\begin{abstract}
Abbreviations
Cl: Confidence interval; MRC: Medical Research Council; MSA: Mannitol Salt Agar; NPS: Nasopharyngeal swab; NVT: Non vaccine type; OR: Odds ratio; PCV (7/13): Pneumococcal conjugate vaccine (7/13) valent; RSV: Respiratory syncytial virus; S. aureus: Staphylococcus aureus; S. pneumoniae: Streptococcus pneumoniae; STGG: Skim milk-tryptone-glucose-glycerol; VT: Vaccine type
\end{abstract}

\section{Acknowledgements}

We would like thank the former principal investigator of the trial, Professor Richard Adegbola, for the design of the main trial. Special thanks goes to Sukai Ceesay and Aji Mary Taal for helping with the laboratory processing of samples, Ma Ansu Kinteh and the rest of field team for collecting the samples. We are also grateful to Miriam Wathuo for helping with the multivariate analysis and responding to some of the reviewers' comments relating to the statistical analysis. Finally, a big thank you to all the participants for agreeing to take part in the study.

\section{Funding}

This work was supported by the Medical Research Council Unit, The Gambia. Study vaccines were donated by Wyeth Lederle Vaccines (Pfizer) and they played no role in the design of the study, writing or decision to publish this manuscript.

\section{Availability of data and materials}

All the raw data supporting the findings can be requested from the corresponding author Dr. Anna Roca.

\section{Authors' contributions}

$B G, P C H, M A$ and $A R$ were involved in study design and collection of data. $A B$ carried out the laboratory experiments. $A B, L K$ and $S M$ analysed the data. $A B, E U$ and $A R$ wrote the manuscript. $A R, M A$ contributed reagents and materials. All authors read and approved the final manuscript.

\section{Ethics approval and consent to participate}

The study was approved by the joint MRC/Gambia Government Ethics Committee and by the ethics committee of the London School of Hygiene \& Tropical Medicine.

Parental consent was obtained for children who participated in the original study

Consent for publication

Not applicable.

\section{Competing interests}

The authors declare that they have no competing interests.

\section{Publisher's Note}

Springer Nature remains neutral with regard to jurisdictional claims in published maps and institutional affiliations.

\section{Author details \\ ${ }^{1}$ Medical Research Council Unit, P. O. Box 273, Fajara, The Gambia. ${ }^{2}$ Faculty of Infectious and Tropical Diseases, London School of Hygiene \& Tropical Medicine, London, UK. ${ }^{3}$ Centre for International Health, School of Medicine, University of Otago, Dunedin, New Zealand. ${ }^{4}$ Faculty of Epidemiology and Population Health, London School of Hygiene and Tropical Medicine, London, UK.}

Received: 12 October 2016 Accepted: 15 August 2017

Published online: 25 August 2017

\section{References}

1. Waters D, Jawad I, Ahmad A, Luksic I, Nair H, Zgaga L, Theodoratou E, Rudan I, Zaidi AK, Campbell H. Aetiology of community-acquired neonatal sepsis in low and middle income countries. J Glob Health. 2011;1(2):154-70.

2. Sigauque B, Roca $A$, Bassat $Q$, Morais $L$, Quinto $L$, Berenguera $A$, Machevo $S$, Bardaji A, Corachan M, Ribo J, et al. Severe pneumonia in Mozambican young children: clinical and radiological characteristics and risk factors. J Trop Pediatr. 2009;55(6):379-87. 
3. Zaidi AK, Thaver D, Ali SA, Khan TA. Pathogens associated with sepsis in newborns and young infants in developing countries. Pediatr Infect Dis J. 2009;28(1 Suppl):S10-8

4. Marwah P, Chawla D, Chander J, Guglani V, Marwah A. Bacteriological profile of neonatal sepsis in a tertiary-care hospital of Northern India. Indian Pediatr. 2015;52(2):158-9.

5. Denison AM, Deleon-Carnes M, Blau DM, Shattuck EC, McDougal LK, Rasheed JK, Limbago BM, Zaki SR, Paddock CD. Molecular characterization of Staphylococcus Aureus and influenza virus coinfections in patients with fatal pneumonia. J Clin Microbiol. 2013;51(12):4223-5.

6. Ramakrishnan K, Salinas RC, Agudelo Higuita NI. Skin and soft tissue infections. Am Fam Physician. 2015;92(6):474-83.

7. Watson K, Carville K, Bowman J, Jacoby P, Riley TV, Leach AJ, Lehmann D, Kalgoorlie Otitis Media Research Project T. Upper respiratory tract bacterial carriage in aboriginal and non-aboriginal children in a semi-arid area of Western Australia. Pediatr Infect Dis J. 2006;25(9):782-90.

8. Bosch AA, Biesbroek G, Trzcinski K, Sanders EA, Bogaert D. Viral and bacterial interactions in the upper respiratory tract. PLoS Pathog. 2013;9(1):e1003057.

9. Wertheim HF, Vos MC, Ott A, van Belkum A, Voss A, Kluytmans JA, van Keulen PH, Vandenbroucke-Grauls CM, Meester MH, Verbrugh HA. Risk and outcome of nosocomial Staphylococcus Aureus bacteraemia in nasal carriers versus non-carriers. Lancet. 2004;364(9435):703-5.

10. Squier C, Rihs JD, Risa KJ, Sagnimeni A, Wagener MM, Stout J, Muder RR Singh N. Staphylococcus Aureus rectal carriage and its association with infections in patients in a surgical intensive care unit and a liver transplant unit. Infect Control Hosp Epidemiol. 2002;23(9):495-501.

11. Gorwitz RJ, Kruszon-Moran D, McAllister SK, McQuillan G, McDougal LK, Fosheim GE, Jensen BJ, Killgore G, Tenover FC, Kuehnert MJ. Changes in the prevalence of nasal colonization with Staphylococcus Aureus in the United States, 2001-2004. J Infect Dis. 2008;197(9):1226-34.

12. Lu PL, Chin LC, Peng CF, Chiang YH, Chen TP, Ma L, Siu LK. Risk factors and molecular analysis of community methicillin-resistant Staphylococcus Aureus carriage. J Clin Microbiol. 2005;43(1):132-9.

13. Hamdan-Partida A, Sainz-Espunes T, Bustos-Martinez J. Characterization and persistence of Staphylococcus Aureus strains isolated from the anterior nares and throats of healthy carriers in a Mexican community. J Clin Microbiol. 2010;48(5):1701-5.

14. Ateba Ngoa U, Schaumburg F, Adegnika AA, Kosters K, Moller T, Fernandes JF, Alabi A, Issifou S, Becker K, Grobusch MP, et al. Epidemiology and population structure of Staphylococcus Aureus in various population groups from a rural and semi urban area in Gabon, Central Africa. Acta Trop. 2012;124(1):42-7.

15. Aires De Sousa M, Santos Sanches I, Ferro ML, De Lencastre $H$. Epidemiological study of staphylococcal colonization and cross-infection in two West African hospitals. Microb Drug Resist. 2000;6(2):133-41.

16. Anwar MS, Jaffery G, Rehman Bhatti KU, Tayyib M, Bokhari SR. Staphylococcus Aureus and MRSA nasal carriage in general population. J Coll Physicians Surg Pak. 2004;14(11):661-4.

17. Amir M, Paul J, Batchelor B, Kariuki S, Ojoo J, Waiyaki P, Gilks C. Nasopharyngeal carriage of Staphylococcus Aureus and carriage of tetracycline-resistant strains associated with HIV-seropositivity. Eur J Clin Microbiol Infect Dis. 1995:14(1):34-40.

18. Roca A, Bojang A, Bottomley C, Gladstone RA, Adetifa JU, Egere U, Burr S, Antonio M, Bentley S, Kampmann B, et al. Effect on nasopharyngeal pneumococcal carriage of replacing PCV7 with PCV13 in the expanded programme of immunization in the Gambia. Vaccine. 2015;33(51):7144-51.

19. Ebruke C, Dione MM, Walter B, Worwui A, Adegbola RA, Roca A, Antonio M. High genetic diversity of Staphylococcus Aureus strains colonising the nasopharynx of Gambian villagers before widespread use of pneumococcal conjugate vaccines. BMC Microbiol. 2016;16(1):38.

20. Roca A, Hill PC, Townend J, Egere U, Antonio M, Bojang A, Akisanya A Litchfield T, Nsekpong DE, Oluwalana C, et al. Effects of community-wide vaccination with PCV-7 on pneumococcal nasopharyngeal carriage in the Gambia: a cluster-randomized trial. PLoS Med. 2011;8(10):e1001107.

21. Davis SM, Deloria-Knoll M, Kassa HT, O'Brien KL. Impact of pneumococcal conjugate vaccines on nasopharyngeal carriage and invasive disease among unvaccinated people: review of evidence on indirect effects. Vaccine. 2013; 32(1):133-45.

22. Ben-Shimol S, Givon-Lavi N, Leibovitz E, Raiz S, Greenberg D, Dagan R. Nearelimination of otitis media caused by 13 -valent pneumococcal conjugate vaccine (PCV) serotypes in southern Israel shortly after sequential introduction of 7-valent/13-valent PCV. Clin Infect Dis. 2014;59(12):1724-32.
23. Ho PL, Chiu SS, Law PY, Chan EL, Lai EL, Chow KH. Increase in the nasopharyngeal carriage of non-vaccine serogroup 15 Streptococcus Pneumoniae after introduction of children pneumococcal conjugate vaccination in Hong Kong. Diagn Microbiol Infect Dis. 2015;81(2):145-8.

24. Collins DA, Hoskins A, Bowman J, Jones J, Stemberger NA, Richmond PC, Leach AJ, Lehmann D. High nasopharyngeal carriage of non-vaccine serotypes in Western Australian aboriginal people following 10 years of pneumococcal conjugate vaccination. PLoS One. 2013;8(12):e82280.

25. Grivea IN, Tsantouli AG, Michoula AN, Syrogiannopoulos GA. Dynamics of Streptococcus Pneumoniae nasopharyngeal carriage with high heptavalent pneumococcal conjugate vaccine coverage in Central Greece. Vaccine. 2011;29(48):8882-7.

26. Bogaert D, van Belkum A, Sluijter M, Luijendijk A, de Groot R, Rumke HC, Verbrugh HA, Hermans PW. Colonisation by Streptococcus Pneumoniae and Staphylococcus Aureus in healthy children. Lancet. 2004;363(9424):1871-2.

27. Dukers-Muijrers NH, Stobberingh E, Beisser P, Boesten RC, Jacobs P, Hoebe CJ. Nasal carriage of Streptococcus Pneumoniae serotypes and Staphylococcus Aureus in Streptococcus Pneumoniae-vaccinated and nonvaccinated young children. Epidemiol Infect. 2012;12:1-8.

28. Kwambana BA, Barer MR, Bottomley C, Adegbola RA, Antonio M. Early acquisition and high nasopharyngeal co-colonisation by Streptococcus Pneumoniae and three respiratory pathogens amongst Gambian new-borns and infants. BMC Infect Dis. 2011;11:175.

29. Kuo CY, Hwang KP, Hsieh YC, Cheng CH, Huang FL, Shen YH, Huang YC, Chiu CH, Chen PY, Lin TY. Nasopharyngeal carriage of Streptococcus Pneumoniae in Taiwan before and after the introduction of a conjugate vaccine. Vaccine. 2011;29(32):5171-7.

30. Bae S, Yu JY, Lee K, Lee S, Park B, Kang Y. Nasal colonization by four potential respiratory bacteria in healthy children attending kindergarten or elementary school in Seoul, Korea. J Med Microbiol. 2012;61(Pt 5):678-85.

31. van Gils EJ, Hak E, Veenhoven $R H$, Rodenburg GD, Bogaert $D$, Bruin JP, van Alphen L, Sanders EA. Effect of seven-valent pneumococcal conjugate vaccine on Staphylococcus Aureus colonisation in a randomised controlled trial. PLoS One. 2011:6(6):e20229.

32. Regev-Yochay G, Trzcinski K, Thompson CM, Malley R, Lipsitch M. Interference between Streptococcus Pneumoniae and Staphylococcus Aureus: in vitro hydrogen peroxide-mediated killing by Streptococcus Pneumoniae. J Bacteriol. 2006;188(13):4996-5001.

33. Regev-Yochay G, Lipsitch M, Basset A, Rubinstein E, Dagan R, Raz M, Malley $R$. The pneumococcal pilus predicts the absence of Staphylococcus Aureus co-colonization in pneumococcal carriers. Clin Infect Dis. 2009;48(6):760-3.

34. Lebon A, Verkaik NJ, de Vogel CP, Hooijkaas H, Verbrugh HA, van Wamel WJ, Jaddoe WW, Hofman A, Hermans PW, Mitchell TJ, et al. The inverse correlation between Staphylococcus Aureus and Streptococcus Pneumoniae colonization in infants is not explained by differences in serum antibody levels in the generation R study. Clin Vaccine Immunol. 2011;18(1):180-3.

35. Usuf E, Bojang A, Hill PC, Bottomley C, Greenwood B, Roca A Nasopharyngeal colonization of Gambian infants by Staphylococcus Aureus and Streptococcus Pneumoniae before the introduction of pneumococcal conjugate vaccines. New Microbes New Infect. 2016;10: $13-8$.

36. Esposito S, Terranova L, Ruggiero L, Ascolese B, Montinaro V, Rios WP, Galeone C, Principi N. Streptococcus Pneumoniae and Staphylococcus Aureus carriage in healthy school-age children and adolescents. J Med Microbiol. 2015;64(Pt 4):427-31.

37. McNally LM, Jeena PM, Gajee K, Sturm AW, Tomkins AM, Coovadia HM, Goldblatt D. Lack of association between the nasopharyngeal carriage of Streptococcus Pneumoniae and Staphylococcus Aureus in HIV-1-infected south African children. J Infect Dis. 2006;194(3):385-90.

38. Esposito S, Marseglia GL, Colombo C, lughetti L, Terranova L, lerardi V, Gambino M, Principi N, Italian Pneumococcal Study Groups on Asthma CF, Diabetes. Interaction between Streptococcus Pneumoniae and Staphylococcus Aureus in paediatric patients suffering from an underlying chronic disease. Int J Immunopathol Pharmacol. 2015;28(4): 497-507.

39. Roca A, Bottomley C, Hill PC, Bojang A, Egere U, Antonio M, Darboe O, Greenwood BM, Adegbola RA. Effect of age and vaccination with a pneumococcal conjugate vaccine on the density of pneumococcal nasopharyngeal carriage. Clin Infect Dis. 2012;55(6):816-24

40. Cutts FT, Zaman SM, Enwere G, Jaffar S, Levine OS, Okoko JB, Oluwalana C, Vaughan A, Obaro SK, Leach A, et al. Efficacy of nine-valent pneumococcal 
conjugate vaccine against pneumonia and invasive pneumococcal disease in the Gambia: randomised, double-blind, placebo-controlled trial. Lancet. 2005;365(9465):1139-46.

41. Bojang A, Jafali J, Egere UE, Hill PC, Antonio M, Jeffries D, Greenwood BM, Roca A. Seasonality of pneumococcal nasopharyngeal carriage in rural Gambia determined within the context of a cluster randomized pneumococcal vaccine trial. PLoS One. 2015;10(7):e0129649.

42. O'Brien KL, Nohynek H, World Health Organization Pneumococcal Vaccine Trials Carriage Working G. Report from a WHO working group: standard method for detecting upper respiratory carriage of Streptococcus Pneumoniae. Pediatr Infect Dis J. 2003;22(2):e1-11.

43. Odutola A, Antonio M, Owolabi O, Bojang A, Foster-Nyarko E, Donkor S, Adetifa I, Taylor S, Bottomley C, Greenwood B, et al. Comparison of the prevalence of common bacterial pathogens in the oropharynx and nasopharynx of gambian infants. PLoS One. 2013:8(9):e75558.

44. Lamikanra A, Paul BD, Akinwole OB, Paul MO. Nasal carriage of Staphylococcus Aureus in a population of healthy Nigerian students. J Med Microbiol. 1985; 19(2):211-6.

45. Roca A, Dione MM, Bojang A, Townend J, Egere U, Darboe O, Howie SR, Hill PC, Adegbola RA, Greenwood BM, et al. Nasopharyngeal carriage of pneumococci four years after community-wide vaccination with PCV-7 in the Gambia: long-term evaluation of a cluster randomized trial. PLoS One. 2013;8(9):e72198

46. Chan GJ, Baqui AH, Modak JK, Murillo-Chaves A, Mahmud AA, Boyd TK, Black RE, Saha SK. Early-onset neonatal sepsis in Dhaka, Bangladesh: risk associated with maternal bacterial colonisation and chorioamnionitis. Tropical Med Int Health. 2013;18(9):1057-64.

47. Chan GJ, Modak JK, Mahmud AA, Baqui AH, Black RE, Saha SK. Maternal and neonatal colonization in Bangladesh: prevalences, etiologies and risk factors. J Perinatol. 2013;33(12):971-6.

48. Skull SA, Krause V, Coombs G, Pearman JW, Roberts LA. Investigation of a cluster of Staphylococcus Aureus invasive infection in the top end of the Northern territory. Aust NZ J Med. 1999;29(1):66-72.

49. Mulholland EK, Ogunlesi OO, Adegbola RA, Weber M, Sam BE, Palmer A, Manary MJ, Secka O, Aidoo M, Hazlett D, et al. Etiology of serious infections in young Gambian infants. Pediatr Infect Dis J. 1999;18(10 Suppl):S35-41.

50. Sherertz RJ, Reagan DR, Hampton KD, Robertson KL, Streed SA, Hoen HM Thomas R, Gwaltney JM Jr. A cloud adult: the Staphylococcus Aureus-virus interaction revisited. Ann Intern Med. 1996;124(6):539-47.

51. Bassetti S, Bischoff WE, Walter M, Bassetti-Wyss BA, Mason L, Reboussin BA, D'Agostino RB Jr, Gwaltney JM Jr, Pfaller MA, Sherertz RJ. Dispersal of Staphylococcus Aureus into the air associated with a rhinovirus infection. Infect Control Hosp Epidemiol. 2005;26(2):196-203.

\section{Submit your next manuscript to BioMed Central and we will help you at every step:}

- We accept pre-submission inquiries

- Our selector tool helps you to find the most relevant journal

- We provide round the clock customer support

- Convenient online submission

- Thorough peer review

- Inclusion in PubMed and all major indexing services

- Maximum visibility for your research

Submit your manuscript at www.biomedcentral.com/submit

) Biomed Central 